\title{
Limitations of the repetition effect revealed by partial report
}

\author{
LIONEL STANDING and FRANK DaPOLITO, Unilersity of \\ Rochester, Rochester, N.Y. 146_7
}

A partial report technique emploving a visual marker was used to study the perceptual repetition effect. The repeated item (one row of a i by ir array) was presented tachistoscopically sereral times, but was not reported by $S$ until a test trial was given. No repetition effect was found when $S$ was required to report another item from the array on cach repetition trial. However, a repetition effect (improved recognition performance) did occur when $S$ was required merely to attend to another item, without response, during the repetition trials. It also occurred when $S$ attended. without response, to the whole array on each repetition trial.

Several studies (e.g., Haber \& Hershenson, 1965; Haber, 1965) have shown that repetition of a tachistoscopic stimulus, at intertrial intervals of several seconds, improves recognition performance greatly. The same improvement with repetition is found for direct ratings of the clarity of the stimulus (Haber \& Hillman, 1966).

It is not known whether the repetition effect is capable of generalization, or is operative only when the identical stimulus is repeated on each trial. Haber (1967) has found that if different three-letter words are flashed on each trial, the probability of seeing a particular letter is a function of whether the previous word had an identical letter in that serial position; thus, it appears that the development of individual letter percepts may at least carry over between separate words.

A further study of generalization processes is attempted within the present experiment, which examines whether the repetition effect can occur for an unreported item which is presented at a randomly varying position within an array on each repetition trial, and also explores the role of attention in the effect. A previous study (Glucksberg \& Ballagura, 1965) has failed to show a repetition effect for unreported items in an array; however, this negative finding is not conclusive.

This study utilizes the partial report technique developed by Sperling (1960) and employs three conditions to test for a repetition effect. In Condition 1, a number of repetition trials are given, in which each stimulus array contains a repeated item; however, $\mathrm{S}$ must respond to some other item in the array, which is indicated for report by a simultaneous visual marker. A test triai is then given on which the previously repeated item is marked and must be reported. Condition 2 follows the same plan, except that $S$ is required merely to attend to the marked item during the repetition trials, and does not respond until the test trial. Condition 3 requires the $S$ to attend to the whole array during the repetition trials, and to report the marked row on test trials. The same stimuli are used for all experimental Ss. In addition, a control condition (4) uses a procedure identical to Condition 2, except that the "repetition" trials use arrays in which no repeated items occur: thus on the test trials, $S$ is required to report a marked item which he has not seen before.

For all groups, a threshold exposure duration is used, so that a repetition effect may be shown as an improved level of recognition performance on test trials.

\section{SUBJECTS}

Twenty-lour experimentally naive psychology undergraduates with normal vision were used as volunteer Ss.

$$
\text { APPARATUS AND STIMULI }
$$

The stimuli were presented in a two-channel tachistoscope (Scientific Prototype 800F), the test and adapting field luminances being $10 \mathrm{~mL}$. Each stimulus was an array of threc rows of three letters each; the letters were randomly selected consonants, except that a single row was sometimes repeated. in a randomly varying position. in several successive arrays. In each array, one row was marked by a large black dot at each end of it. The letters were printed in upper case, with a contrast of .90 ; a central fixation point was provided.

PROCEDURE

Each S's threshold exposure duration was determined at which he was able to report 1.5 letters correctly from the marked row of an array. (This duration averaged about $15 \mathrm{msec}) \mathrm{He}$ was then assigned randomly to one of the four groups. Ss in Group 1 were instructed to report the marked row of each array presented: those in Group 2 were instructed to attend to the marked row on each trial, but not to report it unless, immediately after the trial. E said "respond." (On the other trials, E said "blank.") Ss in Group 3 were instructed to attend to the array as a whole. but to make no report. except on trials where E said "respond" beforehand, in which case they were to report the marked row. Group 4 were given the same instructions as Group 2.

Concerning the stimuli, Ss were told that they were constructed of random strings of consonants. Each experimental $\mathrm{S}$ was shown 100 arrays in a session, comprising 10 totally unique arrays ("one repetition"), 10 series of three successive arrays each containing a common row of three letters ("three repetitions"), and 10 series of six successive arrays each containing a common row ("six repetitions"). The different repetition conditions were given in an order randomized for each S. Control Ss were shown a series of 100 unique arrays. but given for "repetition" and "test" trials in the same manner as Group 2; thus, a control "three-repetition" sequence would comprise three unique arrays, $S$ being required to respond to the third one only. All Ss were tested for two sessions, separated by a day.

\section{RESULTS}

The mean number of letters correctly reported per test trial averaged over the two sessions, is shown in Table 1 for eacl group. Analysis of variance indicated that the effect of repetitions on performance was significant for Groups 2 and 3 $(\mathrm{F}=4.1,2$ and $69 \mathrm{df}, \mathrm{p}<.05)$, but not for Groups 1 and 4 $(F=1.8,2$ and $69 \mathrm{df}, p>.05)$. For the former two groups, recognition perfomance is appreciably above the expected level of 1.5 letters correct per test trial, when three or six repetitions of the test item are used.

\section{DISCUSSION}

The data indicate that the repetition effect does not operate for Group 1, thus supporting the findings of Glucksberg \& Ballagura (1965); material can be present in the short-term visual store or primary image as defined by Sperling (1960) without being transferred to the longer-term memory required for report. However, since the data indicate the occurrence of

Table 1

Mean Number of Letters Reported Correctly per Test Trial, under Experimental Conditions (Groups 1-3), and Control Conditions (Group 4). $N=120$ Observations per Cell.

\begin{tabular}{cccc} 
Group & \multicolumn{2}{c}{ Number of test item repetitions or control trials } \\
1 & $\frac{1}{1.41}$ & 1.44 & 6 \\
2 & 1.66 & 1.81 & 1.45 \\
3 & 1.56 & 1.92 & 1.91 \\
4 & 1.54 & 1.40 & 1.96 \\
\hline
\end{tabular}


a repetition effect for Group 2, it would seem that the crucial factor preventing the repetition effect for Group 1 is not the variation in position of the repeated item during the repetition trials, or the requirement to observe the marked row during repetition trials, but the requirement to respond to the marked row, during the recognition trials. Since the repetition effect is presumably a memory-dependent process, we postulate that the execution of this response leads to disnuption of the process by which visual information is read out of short-term storage into memory (Sperling, 1963).

The improved performance found for Groups 2 and 3 cannot be due simply to their spaced responding (as opposed to the responding on every trial of Group 1), since the control group (4) also responded on intermittent test trials, but showed no improvement. It might be argued that Group 2 showed improvement due to not observing the marked row as instructed, and instead concentrating on the array as a whole; however, this strategy would not improve performance unless $S$ knew exactly in advance the sequence of repetition and test trials. Also, since no impairment of performance is evident on the "one-repetition" condition for this group, this hypothesis appears unlikely.

We conclude tentatively that probably more information is processed-at least partially-from an array than is called for by the partial report indicator, and that the repetition effect is not position dependent. However, the magnitude of the effect found here is not as great as usual, so that further study would be advisable before concluding that this study involves the same form of repetition effect as found in previous investigations.

\section{REFERENCES}

GLUCKSBERG, S., \& BALLAGURA, S. Effects of repetition and intra-array similarity on very short-term memory. Paper presented to Psychonomic Society, 1965.

HABER, R. N. The effect of prior knowledge of the stimulus on word recognition processes. Journal of Experimental Psychology, 1965, 69, 282-286.

HABER, R. N. Interword interaction in the measurement of word recognition. Unpublished research, University of Rochester, 1967.

HABER, R. N., \& HERSHENSON, M. The effects of repeated brief exposures on the growth of a percept. Journal of Experimental Psychology, 1965, 69, 40-46.

HABER, R. N., \& HILLMAN, E. Changes in single letter clarity with repetition. Perception \& Psychophysics, 1966, 1, 347-350.

SPERLING, G. The information available in brief visual presentations. Psychological Monographs: General \& Applied, 1960, 74, 11 (Whole No. 498)

SPERLING, G. A model for visual memory tasks. Human Factors, 1963 , $5,19-31$.

NOTE

1. This research was supported in part by Grants 10753 (Public Health Service) and GB 5910 (National Science Foundation), awarded to R. N. Haber, principal investigator. The assistance of $L$. Rubin in the collection of data is gratefully acknowledged. 